\title{
Undergraduate learning in psychiatry: can we prepare our future medical graduates better?
}

\author{
Vincent Russell* (D), Linda O’Rourke and Kieran C. Murphy \\ Department of Psychiatry, Royal College of Surgeons in Ireland, Dublin, Ireland
}

\begin{abstract}
Irish medical schools attract an increasingly diverse student population and produce graduates who will practise in many parts of the world. There are particular implications in this for the planning and delivery of the undergraduate psychiatry curriculum. In all countries, mental health services struggle for equitable resourcing, and mental health care within general medical services remains relatively neglected. The traditional undergraduate psychiatry offering has been justifiably criticised for being excessively oriented towards secondary care when the vast majority of medical graduates will pursue careers in primary care or in specialties other than psychiatry. Recently published articles in the Irish Journal of Psychological Medicine address the current challenges and opportunities in providing an undergraduate experience that better prepares students for the mental health aspects of medical practice in a global context. We summarise and discuss these contributions and the recent Royal College of Psychiatrists publication Choose Psychiatry: Guidance for Medical Schools.
\end{abstract}

Received 06 January 2020; Revised 19 February 2020; Accepted 24 February 2020; First published online 30 April 2020

Key words: Psychiatry, undergraduate medical education, medical students.

Medical education has become a global industry. Established medical schools in high-income countries, including Ireland, have benefitted from the demand for undergraduate training from countries with recently developed economies. This has enabled our universities to mitigate the impact of cuts in third-level public funding and, in some instances, to establish international campuses. The associated emphasis on recruitment within a competitive international market can be seen as an economic necessity. However, in addition to ensuring that students have acquired essential clinical skills and professional competencies, medical schools should also be socially accountable in producing graduates who are likely to contribute to redressing the enduring problem of global healthcare disparities (Woolard, 2006). There are particular implications in this for those of us involved in planning and delivering the undergraduate curriculum in psychiatry.

The enormous societal burden associated with mental disorders has received belated recognition and the recent addition of mental disorders to the UN's Sustainable Development Goals 2030 is a positive development (Izutsu et al., 2015). Meanwhile, however, countries from which we draw our student population are at various stages of evolution in addressing the historical neglect of mental illness in both primary and secondary care. Major deficits persist in the available numbers of psychiatrists, while mental health

*Address for correspondence: Prof Vincent Russell, Department of Psychiatry, RCSI Education and Research Centre, Smurfit Building, Beaumont Hospital, Dublin 9, Ireland. (Email: vincentrussell@rcsi.ie) training of front-line health professionals remains minimal or absent, especially in low- and middle-income countries (LMICs) (Thornicroft et al., 2016). Only a small minority of our medical graduates will pursue a career in psychiatry. However, many will work in geographic regions in which people with mental illness experience particularly high levels of stigma and discrimination, sometimes within healthcare settings and sometimes in the absence of mental health legislation to protect human rights (Ito et al., 2012). Faced with these challenges, the undergraduate experience in psychiatry should nurture the development of a core professional identity in which values of patient-centred care, equity, and social justice are internalised.

Several recent articles published in the Irish Journal of Psychological Medicine (IJPM) dedicated to the medical education in psychiatry, and including several articles dedicated to the undergraduate curriculum seem timely, all the more so in light of the recent publication by the Royal College of Psychiatrists, "Choose PsychiatryGuidance for Medical Schools" (RCPSYCH, 2019).

Byrne et al.'s comparison of the methods of delivery and assessment of undergraduate psychiatry across the six medical schools in the Republic of Ireland presents a useful national profile (Byrne et al. 2016). It reveals certain strengths, including the adoption of newer pedagogies such as small-group teaching and the use of elearning platforms, reflecting the natural preference of current students as digital natives. However, there is persisting evidence that interest in psychiatry as a career choice often decays in the final medical year (Lyons, 2013, Hor et al., 2020). In this context, the 
authors rightly emphasise the importance of the spiral integration of learning and assessment in psychiatry from year one through to graduation. Here they found significant variation among the six medical schools and notable individual weaknesses. Integrating psychiatry is key, in large part, because the vast majority of students will not choose psychiatry as a career. They must be able, therefore, to recognise and respond to psychiatric presentations at an appropriate level in their day-to-day clinical work, irrespective of the setting in which they practise. The traditional undergraduate psychiatry curriculum has been criticised in the past for delivering content that has limited salience outside specialist psychiatric settings (Lake, 2008). More recent evidence from focus groups among UK medical students revealed the widely held view that there remains an insufficient emphasis on the early introduction of psychiatry and its integration across the curriculum (RCPSYCH, 2019). Efforts to redesign the undergraduate curriculum to better integrate psychiatry appear to improve the students' learning experience as well as their attitudes to the specialty (de Cates et al., 2019). Similarly, the teaching of brief clinical assessment methods for common mental disorders and opportunities to learn psychiatry in non-specialist healthcare settings have been shown to be viable and to provide added educational value (Russell et al., 2018).

Byrne et al. also acknowledge that the psychiatry clerkship exerts a major influence on the individual medical student's future attitudes to people with mental illness and on the likelihood of considering psychiatry as a career (Byrne et al. 2016). Their survey highlights the need for greater understanding of the hidden curriculum within the service settings in which our students are placed, the impact of which is not always positive. Agyapong et al., in their related study from Ghana, address the particular challenge of attracting medical students to a career in psychiatry in LMICs (Agyapong et al. 2019). Their findings mirror those of previous surveys in LMICs, suggesting that stigma per se may have less influence in reducing the appeal of psychiatry than the prospect of relatively lower incomes and poorer working conditions endured by psychiatrists (Kumar et al., 2014).

The article by Mc Manus et al. provides a complementary perspective on the student learning experience at the emotional level (McManus et al. 2019). While reflective learning is now recognised as an essential lifelong activity for physicians, reflective writing predominates at an undergraduate level and elicits a mixed reaction from students (Birden and Usherwood, 2016). McManus et al. describe an initiative whereby fourth year medical students actively participated in a Balint group during their psychiatry clerkship. Their qualitative evaluation suggested positive effects in promoting student empathy and increased self-awareness. These findings demonstrate that reflecting in an interactive peer group can be viable and well received by students. If adequately resourced and supported, Balint groups, already well established within postgraduate psychiatric training, could enhance undergraduate reflective learning as an alternative or in addition to reflective writing (Omer and McCarthy, 2010).

A further opportunity to improve the undergraduate psychiatry learning experience lies in the involvement of patients and carers as educators. In their comprehensive review, Miller et al. present the theoretical argument that higher levels of learning, as articulated in Bloom's taxonomy, are more likely to be attained when the teacher has had personal experience of mental illness (Miller et al. 2016). Their article summarises the limited research in the area and usefully addresses the inherent ethical and administrative challenges. The authors' generally positive conclusions serve as a prompt for curriculum planners to introduce and evaluate service user-facilitated learning experiences within undergraduate psychiatry (Feeney et al., 2013) (Bharathy et al., 2016).

In the introduction to Choose Psychiatry: Guidance for Medical Schools, the Dean of the RCPsych recalls how she was inspired to pursue psychiatry as a career by the teachers she encountered and the learning placements she experienced as a medical student. Many of us who also chose psychiatry will have similarly positive memories. The Guidance was based on the questionnaire surveys and qualitative findings from focus groups with medical students and information sought from faculty leads in medical schools across the UK. It sets out to advise medical schools on how to enhance medical students' experience and identifies four key areas for action: 1 . That medical schools should review their psychiatry curriculum to ensure it reflects students' experience and integrates psychiatry into the curriculum as early as possible. 2. That in providing high-quality clinical placements, feedback on the student experience should inform curriculum design. 3. That the profile of psychiatrists in undergraduate medical education should be raised. 4 . That medical schools should design and implement a range of enrichment activities to enhance students' exposure to and experience of psychiatry.

A helpful feature of the RCPsych Guidance is that at the end of each section it provides checklists containing specific actions required to achieve each of the four recommendations. This could assist medical schools in reviewing their psychiatry curriculum and in identifying specific deficits. Prominent within the qualitative feedback from the students was the request for more mental health content to be included in other medical 
school courses to prevent the perception of psychiatry being separate from what is perceived as "real" medicine. Other suggestions included that students should be better prepared before placements in psychiatry to address their potential fears and negative perceptions of the specialty. This resonates with findings from the literature, and indeed those from Agyapong et al. 2019, as well as the present authors' experience (Agyapong et al. 2019). International students, especially, often seem to commence their psychiatry placements with added anxiety because they strongly associate mental illness with violence (Vasudevan et al., 2015). Another suggestion in the Guidance is that medical schools seek opportunities to work with placement providers to allocate sessions to the range of professionals within the multidisciplinary team. Reassuringly, however, the Guidance emphasises that students continue to value the unique traditional strengths of the psychiatry clerkship, particularly in providing opportunities to talk to patients at length and in-depth about their symptoms and their lives.

One area in which the RCPsych Guidance could be more ambitious is in opportunities for students to contribute to the clinical service. The traditional psychiatry clerkship remains limited in scope, insofar as students are typically exposed to rather than actively involved in the delivery of clinical care. This deprives them of an important sense of agency as adult learners and implicitly overlooks their potential contribution to service quality (Taylor and Hamdy, 2013). A significant percentage of our current medical students are graduate entrants with considerable life experience and often with interesting educational backgrounds and unique skill sets (Pillay et al., 2013). Curriculum planners and medical educators would do well to consider clinical electives, student-run clinics with close faculty supervision and entrusted clinical activities that normalise the mental health aspects of their future clinical role (Thornhill and Tong, 2006) (Murzl et al., 2017).

In their conclusion, Byrne et al. call for greater liaison and sharing of resources in delivering the undergraduate psychiatry curriculum more effectively across the six Irish medical schools. Competitive market forces at work in third-level education may frustrate this worthwhile goal. However, it would seem feasible to achieve greater collaboration between our respective departments of psychiatry in educational research and evaluation. Specifically, the College of Psychiatrists of Ireland, in collaboration with a full representation of faculty from our university medical schools, could develop an Irish guidance document informed by and responsive to local challenges and opportunities. In offering our future graduates a truly transformative undergraduate educational experience in psychiatry, our combined efforts could have a sustained impact beyond the boundaries of our specialty and our country.

\section{Conflict of interest}

Vincent Russell has no conflict of interest to disclose Linda O'Rourke has no conflict of interest to disclose Kieran C. Murphy has no conflict of interest to disclose

\section{Ethical standards}

The authors assert that all procedures contributing to this work comply with the ethical standards of the relevant national and institutional committee on human experimentation with the Helsinki Declaration of 1975, as revised in 2008.

\section{Financial support}

This research received no specific grant from any funding agency, commercial or not-for-profit sectors.

\section{References}

Agyapong VIO, Owusu-Antwi R, Ritchie A, AgyapongOpoku G, Khinda H, Hrabok M, Ohene S, Ulzen T, Osei A (2019). Psychiatry as a specialization: influential factors and gender differences among medical students in a low- to middle-income country. Irish Journal of Psychological Medicine, 1-7. doi: 10.1017/ipm.2019.38

Byrne F, Murphy R, O'Rourke L, Cotter D, Murphy KC, Guerandel A, Meagher D, Sweeney E, Gill M, Campbell A, McDonald C, Hallahan B (2016). A comparison of undergraduate teaching of psychiatry across medical schools in the Republic of Ireland. Irish Journal of Psychological Medicine, 1-12. doi: 10.1017/ipm.2016.22

Bharathy A, Foo PL, Russell V (2016). Changing undergraduate attitudes to mental illness. The Clinical Teacher 13, 58-62.

Birden HH, Usherwood T (2016). "They liked it if you said you cried": how medical students perceive the teaching of professionalism. Medical Journal of Australia 199, 406-409.

De Cates AN, De Cates P, Singh SP, Marwaha S (2019). Can curriculum design influence medical students' attitudes to psychiatry? A comparison of two different approaches. Medical Teacher 41, 939-948.

Feeney L, Jordan I, Mccorran P (2013). Teaching recovery to medical students. Psychiatric Rehabilitation Journal 6, 766-768.

Hor ESL, Russell V, Vasudevan U, O'Brien F (2020). Changing attitudes to psychiatry and interest in the specialty as a career choice during clinical undergraduate years at a medical school in Penang, Malaysia. Irish Journal of Medical Science 189, 253-259. 
Ito H, Setoya Y, Suzuki Y (2012). Lessons learned in developing community mental health care in East and South East Asia. World Psychiatry 11, 186-190.

Izutsu T, Tsutsumi A, Minas H, Thornicroft G, Patel V, Ito A (2015). Mental Health and wellbeing in the sustainable development goals. Lancet Psychiatry 2, 1052-1054.

Kumar A, Mitra K, Nagarajan S, Poudel B (2014). Factors influencing medical students' choice of future specialization in medical sciences: a cross-sectional questionnaire survey from medical schools in China, Malaysia and regions of South Asian Association for Regional Cooperation. North American Journal of Medical Sciences 6, 119-125.

Lake R (2008). How academic psychiatry can better prepare students for their future patients, Part 11: course in ultra-brief initial diagnostic screening suitable for future primary care physicians. Behavioural Medicine 34, 101-116.

Lyons Z (2013). Attitudes of medical students toward psychiatry and psychiatry as a career: a systematic review. Academic Psychiatry 37, 150-157.

McManus S, Killeen D, Hartnett Y, Fitzgerald G, Murphy KC 2019. Establishing and evaluating a Balint group for fourth-year medical students at an Irish University. Irish Journal of Psychological Medicine, 1-7. doi: 10.1017/ipm. 2019.28

Murzl CA, Durns TA, Mowrey LT, Tubbs AS, Boeve SA (2017). A medical student-run child and adolescent psychiatry clinic: one institution's experience. Academic Psychiatry 41, 582-586.

Miller C, Pradeep V, Mohamad M, Izmeth Z, Reynolds MTP, Gulati G (2016). Patients and carers as teachers in psychiatric education: a literature review and discussion.
Irish Journal of Psychological Medicine, 1-8. doi: 10.1017/ ipm.2016.45

Omer S, Mccarthy G (2010). Reflective practice in psychiatric training: Balint groups. Irish Journal of Psychological Medicine 27, 115-116.

Pillay SM, Sundram F, Mullins D, Rizvi N, Grant T, Boohan M, Murphy KC (2013). Non-graduate and graduate entry medical students attitudes to psychiatry. Irish Journal of Psychological Medicine 30, 245-254.

RCPSYCH (2019). Choose Psychiatry: Guidance for Medical Schools. London: Royal College of Psychiatrists.

Russell V, Clarke M, Loo C, Bharathy A, Vasudevan U, Byrne E, Smith S (2018). Medical Student perceptions of the value of learning psychiatry in primary care settings in Penang, Malaysia. Academic Psychiatry 1-10.

Taylor D, Hamdy H (2013). Adult learning theories: implications for learning and teaching in medical education. Medical Teacher 35, e1561-e1572.

Thornhill JT, Tong L (2006). From Yoda to Sackett: the future of psychiatry medical student education. Academic Psychiatry 30, 23-28.

Thornicroft G, Deb T, Henderson C (2016). Community mental health care worldwide: current status and further developments. World Psychiatry 15, 276-286.

Vasudevan U, Bharathy A, Min KJ, Panikulam JJ, Saleem F, Hassali A, Russell V (2015). Malaysian medical students' perceptions of a film to promote psychiatry as a career. Australasian Psychiatry 23, 173-176.

Woolard RF (2006). Caring for a common future: medical schools' social accountability. Medical Education 40, 301-313. 